\title{
Research on the Current Situation of Scientific Talents of Photovoltaic Industry and the Influencing Factors in Yangtze River Delta Region
}

\author{
Ming Chen \\ School of Economics, Shanghai University, 99 Shangda Road, Shanghai, China \\ shuolivia@163.com
}

Keywords: Yangtze River Delta; Photovoltaic industry; Talent policy; Economic Development

\begin{abstract}
This paper will analyze and summarize the current situation of photovoltaic industry scientific talents in the Yangtze River Delta, in a way of principal component analysis, and based on the basic information obtained by a questionnaire survey and field research. According to the current situation summarized by interviews and the first-hand information obtained through questionnaires and surveys, this paper makes recommendations in policy respectively from aspects of cities, industries and enterprises, striving to compensate the lack of policy for talents in photovoltaic industry, to perfect the policies of attracting scientific and technological personnel in Yangtze River Delta and to provide a theoretical basis for a healthier development of photovoltaic industry in Yangtze River Delta.
\end{abstract}

\section{Introduction}

Under the background of frequent national talent policies, the importance of scientific and technological talents is growing more and more prominent. As a new industry, photovoltaic industry has a relatively large advantage in energy utilization and environmental protection. Hence, this industry has gradually become one that the government provides shelter for, and scientific and technological talents are willing to flow to. Ahmad Zahedi [1] believes energy is the key factor to promote the development of the world and to improve the living standard of human life. The analytical framework built by Zhang Pengchao [2] using ERG theory, divides China's incentive policy of photovoltaic industry into security policy, promotion policy and coordination policies etc. Wu Zhi Jun and Wang Yang ${ }^{[3]}$ hold that so far the policy direction of photovoltaic industry in China needs to be adjusted as soon as possible, since Chinese current situation of photovoltaic policy existing problems of macro policy, and lack of incentive policies both in research and development and in economy. In view of current situation, there is little research on talents' status of this emerging industry. Human resources adapting to the development of a country or a region is significantly important in gaining competitive advantage, and whether a country or a region can achieve suitable talents depends on the attractions of talent. Regions, industries and enterprises play an important role in the process of attracting talents, and understanding this point in a scientific way is significant to human resources utilization.

\section{Description and Presentation of the Questionnaire}

Questionnaires in perspective of technical personnel includes 3 items, and 89 specific items, in perspective of enterprise management personnel includes 3 items, and 37 specific items, the perspective of human resources questionnaire includes 6 items and 20 specific items. The Liket5 method is used, in which 5 means agree or satisfied very much, 4 agree or satisfied, 3 moderate or neutral, 2 not agree or not satisfied, 1 not agree or dissatisfied very much.

\section{Evaluation Method}

Modern comprehensive evaluation methods mainly include analytic hierarchy process (AHP), principal component analysis (PCA), and data envelopment analysis (DEA) and so on. Considering that the AHP needs to determine the relative importance of assessment indexes to construct the 
judgment matrix, and the DEA needs to select the input index and output index, both are likely to result in subjectivity. In contrast, the PCA does not exist the problem of subjectivity, it will determine the corresponding principal components (linear combination of the original variables), only according to the amount of information each index (variable) actually carried and decide the corresponding importance of each index. The evaluation process is based on the actual value of each index in the evaluation system, and does not involve the subjective judgments of evaluators. Therefore, this report adopts the PCA method to carry out the evaluation of city characteristics, industry characteristics and enterprise characteristics, as far as possible to give an objective and fair evaluation results.

\section{Influence Factors of Urban, Industrial and Enterprise Characteristics on Scientific and Technological Personnel of Photovoltaic Industry}

Reliability Analysis. Reliability analysis mainly evaluates the internal consistency coefficient of questionnaires, and this paper adopts Cronbach's alpha coefficient, testing the consistency of 66 items of researchers and 18 items management personnel. Overall credibility is relatively high. So reliability in this survey is basically in a good level. Samples are passed the KMO and SMC test, suitable for the analysis of the composition (greater than 0.6 is appropriate, the closer to 1 , the better).

The results shows that city affects most when scientific and technological talents select jobs, which accounts for $40 \%$, and the industry and enterprise respectively accounts for $22 \%$ and $38 \%$. In detail, the urban living environment, industry government support, the enterprise development prospect, urban talent policies are attached more attention by the scientific and technological talents. The urban cultural environment, the enterprise working characteristics, and the enterprise welfare and so on, have little influence on the scientific and technological personnel.

City Dimension. The results show that the main factors affecting the urban attraction of the Yangtze River Delta are: life pace, the policy of settling down, the price level, the condition of public facilities and the education of the children, consistent with the results of first step.

Industry Dimension. In view of photovoltaic industry in the Yangtze River Delta, the influence of government supports, industry prospects and whether it is easy to settle down are the most important factors to evaluations of science and technology personnel.

Enterprise Dimension. In view of enterprise, exchange opportunities between peers, corporation reputation, the strength of enterprise and the management ability weight higher than others.

Analysis of Dimensions. In order to directly determine which index is the worst, we construct a concept of weight * average value, observing the specific indicators by the product of the average value multiplied by weight, and screening important factors of attractiveness.

In of view the final comprehensive score, public facilities, life pace and policy for settlement have become the most important factors, and the cultural environment other factors score lower.

On the whole, the average high and the power of the government support that both the average value and weight score much higher the industry prospects rank front, while the industry salary and extra welfare score the lowest.

Hence, the weight of urban factors, industry factors and the enterprise factors respectively are $0.4,0.22,0.38$, and it can be concluded that the comprehensive score of attraction to talents in Yangtze River photovoltaic industry is 0.61 , between medium and good level.

Contrast Analysis. Management personnel looks at the attractiveness of the talent is bound to be different from personnel in science and technology, the management one pays more attention to the future development of the enterprise, cost control and competitive advantage compared to other similar enterprises, and combines with its own characteristics to make the strategies of enterprises development with revenue.

In view of the average score, the overall management personnel believe that the evaluation of scientific and technological personnel is relatively overvalued compared with the evaluation in fact. Particularly, reflected in the urban dimension and industry dimension. 
On the whole, two groups have different views, the management personnel believes that scientific and technological personnel is more optimistic to the city and the industry, while actual situation is more severe. In perspective of the enterprise, managers underestimate the recognition of scientific and technical personnel to enterprises. And views of managers who get along with scientific and technological personnel in basic level are not the same, then whether the policy of government departments can ensure that scientific and technological personnel generates a sense of belonging? Management personnel and government departments should understand the actual needs of the talents in-depth, increase salary both of industry and enterprise, perfect enterprise incentive system, breaking the situation of "strong working intensity, but low pay", this may be one of the key factors to the attractions of city, industries and enterprises to talents.

\section{Conclusion}

Judgment and Summary of the Current Situation of Talents in Photovoltaic Industry in the Yangtze River Delta. In view of information from samples and surveys simply, talents of photovoltaic technology in Yangtze River Delta give us the following impression:

Young Staff. According to the information reflected in the sample, we can see that the amount of talents under the age of 35 years accounts for more than $74 \%$, showing photovoltaic industry very young. Indirectly reflects that the industry's accumulated precipitation is not enough.

High Educational Background. In view of educational background, the number of talents of bachelor degree or above accounts for more than eighty percent, of master's degree also accounts for $33 \%$, indicating that the attraction of photovoltaic industry to talent is quite good, and the middle foundation is much solid. Similar to other industries, talents of doctor degree in the photovoltaic industry are also scarce.

Concentration of Local Characteristics. In view of cities where obtain the highest degree and whether studied abroad, we can see that the localization of scientific and technological talents is too strong, too few overseas talents, especially in management level. This shows that this industry is not a particularly strong international one. If photovoltaic industry wishes to achieve corner overtaking, it must combine with the international trend of scientific and technological progress.

Little Communication between Peers. The communication of research personnel in photovoltaic field with external personnel is insufficient, and this item in the questionnaire obtains lower scores. According to the interview, the exchanges and cooperation between enterprises, enterprises with universities and research institutes are relatively insufficient, which hinders the progress of talents indirectly.

Low Salary and Welfare. As can be seen from the questionnaire and interviews, most of the researchers are not very satisfied with the salary and welfare. On the one hand, the industry is much younger. On the other hand, most of the company's salary structure is stable, lacking of incentive mechanism

Full of Spirits of Dedication. Technical personnel in photovoltaic field in Yangtze River Delta are full of spirits of dedication. On the one hand, it reflects the recognition of the industry and the company. Most of the scientific and technological personnel think that the industry has a good prospect and hold a high evaluation of various aspects of the company, and the vast majority of researchers do not want to do job hopping. On the other hand, we also find that the enterprise maintains a good research atmosphere, a clear division of scientific research personnel, and the personnel enjoy a high passion for work.

Overall, the development prospects of the photovoltaic industry present a vigorous trend.

\section{References}

[1] Ahmad Zhmaedi. "Energy, People, Environment" Development of an integrated renewable energy \& energy storage system, an uninterruptable power supply for people and for better environment [C], Systems, Man, and Cybernetics, 1994.Humans, Information and Technology.1994 IEEE International Conference on(Volume:3),1994(3):2692-2695 
[2] Zhang Pengchao. Study on the incentive policy of photovoltaic industry in China [D]. North China Electric Power University

[3] Wu Zhijun, Wang Yang. Reflection on China's industrial policies and proposals of photochemical West Social Science (.2013 10)

[4] Wang Yi. Personnel policy innovation should have new thinking [J]. Chinese talent, 2014 (8): 54-55

[5] Ju Wei, Liu Ning. A comparative study on talent policy of Beijing Shanghai Guangdong Zhejiang Jiangsu [J]. policy analysis, 2014

[6] Liu Deyan, Wang Lili. System innovation of the introduction of overseas scientific and technological talents in China [J]. Science and technology progress and countermeasures, 2005 (9): 114-116.

[7] Sally Chan, Li Minglu. Study on regional comparison and policy structure preference of talent policy [J]. China Science and Technology Forum, 2009 (9): 107-111.

[8] Xie Qiaojie. Yangtze River Delta talent policy among thirty years: evolution and development of talent innovation [J]. 2009 (4): 8-10.

[9] Hu Peng. Preliminary study on the construction of the new talent policy system in Yangtze River Delta [J]. theoretical science, 2009

[10] Yang Nanzhen. Seize the opportunity and accelerate the development of photovoltaic in the Yangtze River Delta and [J]. Power and energy, 2012 (6): 207-301.

[11]Ren Dongming. China PV industry development and institutional innovation [J]. Chinese and foreign energy, 2011 (1): 31-36.

[12]Wang Weidong, Ai Jianjun, Yang Kun. Problems and Countermeasures of talent cultivation in photovoltaic industry [J]. China Electric Power Education, 2011 (12): 5-6. 